\title{
Optimal Design of Single-Tuned Passive Filters Using Response Surface Methodology
}

\author{
Selcuk Sakar ${ }^{1}$, Aslan Deniz Karaoglan ${ }^{2}$, Murat Erhan Balci ${ }^{3}$, Shady H. E. Abdel Aleem ${ }^{4}$, Ahmed F. Zobaa ${ }^{5}$ \\ ${ }^{1}$ Department of Electrical and Electronics Engineering, Gediz University- Izmir, Menemen, Izmir, Turkey, \\ selcuk.sakar@gediz.edu.tr \\ ${ }^{2}$ Department of Industrial Engineering, Balıkesir University, Balıkesir, Turkey, deniz@balikesir.edu.tr \\ engyshady@ieee.org \\ ${ }^{3}$ Department of Electrical and Electronics Engineering, Balıkesir University, Balıkesir, Turkey \\ ,mbalci@balikesir.edu.tr \\ ${ }^{4}$ Mathematical, Physical and Life Sciences, 15th of May Higher Institute of Engineering, Cairo, Egypt, \\ engyshady@ieee.org \\ ${ }^{5}$ College of Engineering, Design \& Physical Sciences, Brunel University, London, Uxbridge, United Kingdom,
} azobaa@ieee.org

\begin{abstract}
This paper presents an approach based on Response Surface Methodology (RSM) to find the optimal parameters of the single-tuned passive filters for harmonic mitigation. The main advantages of RSM can be underlined as easy implementation and effective computation. Using RSM, the single-tuned harmonic filter is designed to minimize voltage total harmonic distortion (THDV) and current total harmonic distortion (THDI). Power factor (PF) is also incorporated in the design procedure as a constraint. To show the validity of the proposed approach, RSM and Classical Direct Search (Grid Search) methods are evaluated for a typical industrial power system.
\end{abstract}

Keywords - Harmonic mitigation, power factor improvement, passive harmonic filters, response surface methodology.

\section{NOMENCLATURE}

$V_{h}, I_{h}: h^{\text {th }}$ harmonic voltage and current phasors,

$V_{h}, I_{h}: h^{\text {th }}$ harmonic voltage and current $r m s$ values,

$\varphi_{h}$ : Phase angle difference between $h^{\text {th }}$ harmonic voltage and current,

$Y_{u}$ : The corresponding response,

$X_{i u}$ : Coded values of the $i^{\text {th }}$ input parameters,

$\beta_{0}$ : Constant of regression equation,

$\beta_{i}$ : Regression coefficients of linear terms,

$\beta_{i i}$ : Regression coefficients of square terms,

$\beta_{i j}$ : Regression coefficients of interactions,

$e_{u}$ : The residual experimental error of the $u^{\text {th }}$ observation.

\section{INTRODUCTION}

Harmonic distortion of voltage and current waveforms significant concerns today's power systems due to the large proliferation of the nonlinear loads, or harmonic producing loads [1]. The basic capacitors may not provide the desired power factor value under the harmonically distorted voltage and current conditions [2], [3]. Thus, regarding harmonic mitigation and reactive power compensation, passive and active filters have been presented in the literature [4]-[6]. Active filters have superior performance on harmonic mitigation and power factor correction when compared to the passive filters [4]. However, they suffer from high costs [4] and require advanced control algorithms [7]-[9]. Accordingly, passive filters are still extensively used in the industry [10].

Since power factor, current harmonic distortion, voltage harmonic distortion, filter loss and filter investment cost can be contradictory to each other, the design of passive filters is not a straightforward problem. Accordingly, in the literature, minimization of current total harmonic distortion (THDI) and/or voltage total harmonic distortion (THDV) [11]-[16], power factor (PF) maximization [17]-[21] and minimization of the filter investment cost (FC) and/or filter loss (FL) objectives [22]-[24] were taken into account for optimal passive filter design. In [25], the optimal passive filter design problem has an objective as minimization of FC and THDV. Reference [26] aimed to achieve minimization of FC, THDV and THDI. [27] and [28] employed passive filters for minimization of the objective function including FC, FL, THDI and THDV. In [29], four objectives as maximization of $\mathrm{PF}$ and minimization of FC, THDV and THDI are collectively considered to find optimal passive filter design. In addition to the above mentioned approaches, [30] and [31] employed passive filters for minimization of the harmonic loss factor or maximization of transformer's loading capability under harmonically contaminated load current conditions.

In these studies, the heuristic methods such as the differential evolution (DE) [13], [14], [22], [26], genetic algorithms [18], [19], [25] and particle swarm optimization method [15], [16], [27], [28] were extensively utilized to solve the optimal passive filter design problem. The most important advantage of the heuristic methods is that they provide a reasonable solution (near globally optimal) in a short time or less iterations [32]. However, their results are sensitive to a large number of specific parameters, which are set by 
designers. Therefore, the specific parameters should be well determined for the success of the methods.

RSM is a statistical technique, which is employed to obtain the functional relationships between the inputs and outputs of a system [33], [34]. In the terminology of experimental design, the inputs and outputs are called as the factors and the responses, respectively. By using the functional relationships based on RSM, the optimal filter design problem can be solved with less computational effort [12]. In addition to that, due to the fact that there is no need for any specific parameter setting in the optimization process with RSM, its implementation is quite straightforward when it is compared to the above mentioned heuristic methods.

This paper presents an application of RSM for the solution of the multi-objective optimization problem of shunt single-tuned passive filters. The purpose is to minimize THDV and THDI while holding PF at its desired value. The major attribute of the proposed approach is that it can easily be implemented for computational efficient solution of the problem.

\section{ANALYSIS OF THE SYSTEM UNDER STUDY}

A typical industrial power system is considered to demonstrate the proposed multi-objective optimization approach based on RSM. The single-line diagram of the considered system, which consists of a transformer, the consumer with the linear and nonlinear loads and LC filter connected to load bus, is shown in Figure 1. By taking into account its single-phase equivalent circuit given in Figure 2, the voltage, current and powers can practically be calculated. In the single-phase equivalent circuit, the linear and nonlinear loads are modelled as the parallel connection of an impedance $\left(R_{L}+j h X_{L}\right)$ and constant current sources as per harmonics ( $I_{L h}$ ) [35], [36]. For each harmonic, utility side is represented as Thevenin equivalent voltage source $\left(\underline{V}_{s h}\right)$ and Thevenin equivalent impedance $\left(\underline{Z}_{S h}\right)$, which is seen from the load bus.

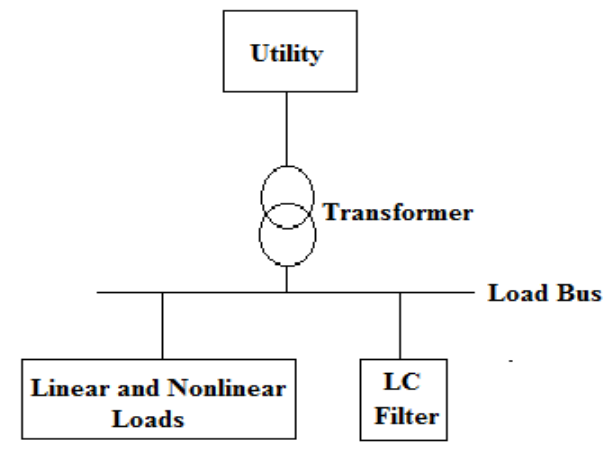

Fig. 1: A typical industrial power system.

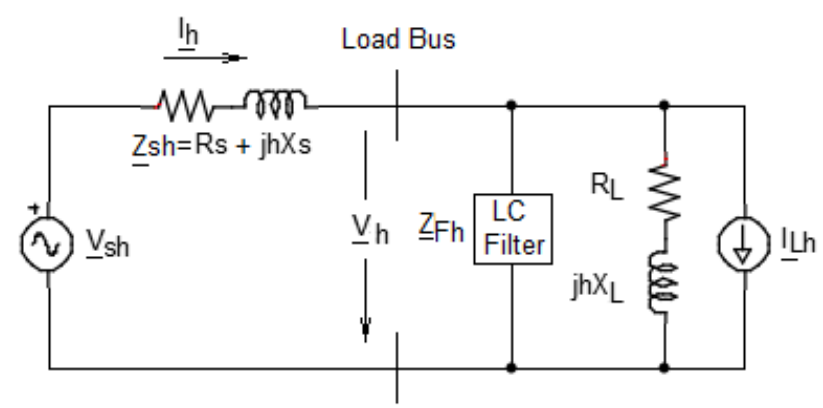

Fig. 2: The single-phase equivalent circuit of the considered system.

As a result, the following current and voltage equations can be written for the single-phase equivalent circuit of the system using the superposition principle, as follows:

$\underline{I}_{h}=\frac{\underline{V}_{S h}}{\underline{Z}_{S h}+\underline{Z}_{F L h}}+\frac{\underline{Z}_{F L h}}{\underline{Z}_{S h}+\underline{Z}_{F L h}} \underline{I}_{L h}$

$\underline{V}_{h}=\underline{V}_{S h}-\underline{I}_{h} \underline{Z}_{S h}$

where $\underline{Z}_{F L h}$ is the equivalent of the load side's $h^{\text {th }}$ harmonic impedance $\left(R_{L}+j h X_{L}\right)$ and $h^{\text {th }}$ harmonic impedance of single-tuned LC filter $\left.\underline{Z}_{F h}=j\left(h X_{L F}-\frac{X_{C F}}{h}\right)\right)$ :

$\underline{Z}_{F L h}=\frac{\underline{Z}_{F h}\left(R_{L}+j h X_{L}\right)}{\left(\underline{Z}_{F h}+R_{L}+j h X_{L}\right)}$

Note that the subscript ( $\_$) denotes phasor values of the respective voltage, current and impedances.

Considering the voltage and current harmonics found from (1) and (2), voltage and current total harmonic distortions (THDV and THDI) can be calculated as follows:

$$
\begin{gathered}
T H D V=\frac{\sqrt{\sum_{h \neq 1} V_{h}^{2}}}{V_{1}} \\
T H D I=\frac{\sqrt{\sum_{h \neq 1} I_{h}^{2}}}{I_{1}}
\end{gathered}
$$

Using the voltage and current quantities, one can also express active and apparent powers consumed by the load:

$$
\begin{aligned}
P & =\sum_{h} V_{h} I_{h} \cos \varphi_{h} \\
& =V_{1} I_{1} \cos \varphi_{1}+\sum_{h \neq 1} V_{h} I_{h} \cos \varphi_{h}=P_{1}+P_{H} \\
S & =\sqrt{\sum_{h} V_{h}^{2}} \sqrt{\sum_{h} I_{h}^{2}} \\
& =V_{1} I_{1} \sqrt{1+\frac{\sum_{h \neq 1} V_{h}^{2}}{V_{1}^{2}}} \sqrt{1+\frac{\sum_{h \neq 1} I_{h}^{2}}{I_{1}^{2}}}=S_{1} \sqrt{1+T H D V^{2}} \sqrt{1+T H D I^{2}}
\end{aligned}
$$

Thus, in terms of these powers, displacement power factor (DPF) and power factor (PF) can be found:

$$
D P F=\frac{P_{1}}{S_{1}}
$$




$$
P F=\frac{P}{S}=\frac{P_{1}+P_{H}}{S_{1} \sqrt{1+T H D V^{2}} \sqrt{1+T H D I^{2}}}
$$

By means of the above mentioned voltage and current relations, power quality indices and power quantities, the multi-objective optimization problem of single-tuned passive filter will be formulated and solved for the studied system in the next sections.

\section{FORMULATION OF OPTIMAL FILTER DESIGN PROBLEM}

The design of a harmonic filter, which minimizes voltage and current total harmonic distortions, should be useful to prevent malfunctions of the harmonic sensitive system equipments. Accordingly, this paper aims to provide optimal passive harmonic filter for the minimization of THDI and THDV in the studied system. THDI and THDV indices are also considered as two constraints in the optimization problem due to the fact that in IEEE Std. 519-2014 [37] both indices are taken under limitation for several levels of the supply voltage and short circuit power of the system. On the other hand, in various countries, utilities charge consumers an extra fee if their PF is less than 90\% [38]. Thus, PF becomes a third constraint of the optimization problem.

Hence, considering the presented objectives and constraints, design of the harmonic filter can be formulated as a multi-objective optimization problem as follows:

Find: $X_{C F}$ and $X_{L F}$ values of the passive filter to minimize,

$$
f\left(X_{L F}, X_{C F}\right)=w_{1} T H D V+w_{2} T H D I
$$

Subjected to:

$0 \leq T H D I \leq$ Maximum allowable THDI (IEEE Std. 519), $0 \leq T H D V \leq$ Maximum allowable THDV (IEEE Std. 519), $90 \% \leq P F \leq 100 \%$.

where $w_{1}$ and $w_{2}$ denotes the weighting factors of the objectives, which are assumed equal $\left(\omega_{1=} \omega_{2}=0.5\right)$.

\section{NUMERICAL EXAMPLE}

As mentioned before, proposed design approach based on RSM has been demonstrated for the system given in Figure 1. For the demonstration, the fundamental frequency supply bus voltage and short circuit power of the system are predetermined as $4.16 \mathrm{kV}$ (line-to-line) and 175 MVA. In the exemplary system without filter, power quality indices and power quantities, measured at the load bus, are presented in Table I.

TABLE I

POWER QUALITY INDICES AND POWER QUANTITIES CALCULATED FOR THE SYSTEM WITHOUT PASSIVE FILTER

\begin{tabular}{cccccc}
\hline THDV & THDI & DPF & $P F$ & $P_{l}$ & $S_{I}$ \\
\hline $4.98 \%$ & $10.06 \%$ & $72.82 \%$ & $72.27 \%$ & $5058 \mathrm{~kW}$ & $6947 \mathrm{kVA}$ \\
\hline
\end{tabular}

According to the modelling issues presented in section II, for the single-phase equivalent circuit of the system, the impedance parameters and the harmonic spectrums of voltage and current sources are given in Table II. For the equivalent circuit, fundamental frequency line-to-neutral source voltage $\left(V_{S I}\right)$ and fundamental frequency line current $\left(I_{l}\right)$ are calculated as $2400 \mathrm{~V}$ and $995.92 \mathrm{~A}$.

\section{TABLE II}

THE IMPEDANCE PARAMETERS

AND THE HARMONIC SPECTRUMS OF VOLTAGE AND CURRENT SOURCES

\begin{tabular}{clc}
\hline $\begin{array}{c}\text { Impedance } \\
\text { Parameters }(\Omega)\end{array}$ & $\begin{array}{c}\text { Voltage Source } \\
\text { Harmonics (V) }\end{array}$ & $\begin{array}{c}\text { Current Source } \\
\text { Harmonics (A) }\end{array}$ \\
\hline$R_{L}=1.7$ & $\underline{V}_{S 5}=48 \angle 0^{\circ}$ & $\underline{I}_{L 5}=99.56 \angle 135^{\circ}$ \\
$X_{L}=1.6$ & $\underline{V}_{S 7}=48 \angle 0^{\circ}$ & $\underline{I}_{L 7}=44.79 \angle 45^{\circ}$ \\
$R_{S}=0.01$ & $\underline{V}_{S 11}=24 \angle 0^{\circ}$ & $\underline{I}_{L 11}=19.91 \angle-135^{\circ}$ \\
$X_{S}=0.1$ & $\underline{V}_{S 13}=24 \angle 0^{\circ}$ & $\underline{I}_{L 13}=9.95 \angle 135^{\circ}$ \\
\hline
\end{tabular}

IEEE Std. 519 recommended limits for THDV and THDI levels of the exemplary system are $5 \%$ and $8 \%$. It is seen from Table I that the THDI limit, according to the standard, is not satisfied. In addition, the system has very low PF percentage, $72.27 \%$. Thus, a passive filter should be employed for both power factor correction and harmonic mitigation in the exemplary case.

\section{A. Application of RSM to Solve Formulated Optimization Problem}

For the solution of the optimal filter design problem, RSM can be performed to establish the mathematical relationships between the responses (PF, THDI, THDV) and the factors $\left(\mathrm{X}_{\mathrm{LF}}\right.$ and $\left.\mathrm{X}_{\mathrm{CF}}\right)$. To obtain these mathematical relationships, initial experiments should be done for actual and corresponding coded values of $\mathrm{X}_{\mathrm{LF}}$ and $\mathrm{X}_{\mathrm{CF}}$, which are given in Table III. For the initial experiments, the intervals of $\mathrm{X}_{\mathrm{LF}}$ and $\mathrm{X}_{\mathrm{CF}}$ values can be set by considering filter's tuning harmonic order ( $\left.h_{t}=\sqrt{X_{C F} / X_{L F}}\right)$ around the dominant harmonic order $(\mathrm{h}=5)$ of the system and the DPF interval (95\%-100\% lagging). Consequentially, calculated THDV, THDI and PF values are presented in Table IV. Here it should be noted that the design type is selected as the central composite face centered RSM design. The selected design type requires standard 8 experiments for cube and axial points and 1 experiment (custom) for the center point $(0,0)$, with totally 9 experiments.

Equation (10) shows the general second-order polynomial response surface mathematical model (full quadratic model) for the experimental design [33], [34] [39]:

$$
\begin{gathered}
Y_{u}=\beta_{0}+\sum_{i=1}^{n} \beta_{i} X_{i u}+\sum_{i=1}^{n} \beta_{i i} X_{i u}^{2}+\sum_{i<j}^{n} \beta_{i j} X_{i u} X_{j u}+e_{u} \\
\text { TABLE III }
\end{gathered}
$$

LIST OF ACTUAL AND CORRESPONDING CODED VALUES OF XLF AND XCF FOR THE INITIAL EXPERIMENTS

\begin{tabular}{cccc} 
Level & $\mathbf{- 1}$ & $\mathbf{0}$ & $\mathbf{1}$ \\
\hline $\mathrm{X}_{\mathrm{LF}}(\Omega)$ & 0.1000 & 0.2000 & 0.3000 \\
$\mathrm{X}_{\mathrm{CF}}(\Omega)$ & 2.0000 & 3.0000 & 4.0000 \\
\hline
\end{tabular}


TABLE IV

DESIGN OF EXPERIMENTS MATRIX SHOWING CODED VALUES AND OBSERVED RESPONSES FOR INITIAL EXPERIMENTS

\begin{tabular}{ccccc}
\hline $\mathbf{X}_{\mathbf{L F}}$ & $\mathbf{X}_{\mathbf{C F}}$ & THDV & THDI & PF \\
\hline-1 & -1 & 1.4444 & 8.4824 & 79.8442 \\
1 & -1 & 3.3713 & 5.3411 & 72.4918 \\
-1 & 1 & 6.4472 & 53.5934 & 87.6100 \\
1 & 1 & 3.1577 & 6.5501 & 99.3904 \\
-1 & 0 & 1.4601 & 19.5762 & 96.8854 \\
1 & 0 & 3.3051 & 6.7951 & 96.7501 \\
0 & -1 & 2.8133 & 4.7540 & 76.4110 \\
0 & 1 & 2.1787 & 8.2315 & 99.1444 \\
0 & 0 & 2.5672 & 6.3465 & 97.7087
\end{tabular}

MINITAB 16 statistical package [39] is used to establish the mathematical models for minimizing THDV and THDI while holding PF at its desired percentage (90\%). In the optimization process, it is considered that the THDV and THDI percentages must meet the limits specified in IEEE Std. 519 (5\% and 8\%, respectively). According to the results of the initial experiments (Table IV), mathematical models based on RSM for correlating responses such as the THDV, THDI and PF have been established with $95 \%$ confidence, and are represented in the following regression equations (11)-(13) with $R^{2}$ value (coefficient of determination) of $66.72 \%, 90.35 \%$ and $98.54 \%$, respectively.

$$
\begin{aligned}
T H D V= & 1.9922+0.0804 X_{L F}+0.6924 X_{C F}+0.6779 X_{L F}^{2} \\
& +0.7913 X_{C F}^{2}-1.3041 X_{L F} X_{C F} \\
T H D I= & 4.0530-10.4940 X_{L F}+8.3000 X_{C F}+10.2790 X_{L F}^{2} \\
& +3.5860 X_{C F}^{2}-10.9760 X_{L F} X_{C F} \\
P F= & 98.6210+0.7154 X_{L F}+9.5663 X_{C F}-2.2594 X_{L F}^{2} \\
- & 11.2994 X_{C F}^{2}+4.7832 X_{L F} X_{C F}
\end{aligned}
$$

Using (11)-(13), the contours of responses for THDV, THDI and PF are plotted in Figure 3 (a), (b) and (c). When the contours of three responses are superimposed on each other, it is seen that the solution of the formulated optimization problem can be found in the region, which is limited by the coded $X_{L F}$ values between -0.5 and 0.5 and the coded $X_{C F}$ values between -0.6 and 0 . Thus, the parameter set of $X_{L F}$ and $X_{C F}$, which were given in Table III, should be updated. Thus, a new parameter set is determined as shown in Table V. Accordingly, the second experiment results, which are obtained with respect to the new parameter set, are presented in Table VI.

Using the new (second) experimental results presented in Table VI, for the correlating responses THDV, THDI and PF the models have been established with 95\% confidence, and are expressed as in (14)-(16) with $R^{2}$ values of $99.99 \%, 98.60 \%$, and $100.00 \%$, respectively.

$$
\begin{aligned}
T H D V= & 2.6562+0.5253 X_{L F}-0.0907 X_{C F}-0.1191 X_{L F}^{2} \\
& -0.0059 X_{C F}^{2}+0.0474 X_{L F} X_{C F}
\end{aligned}
$$

$$
\begin{aligned}
\text { THDI }= & 5.9548-0.9168 X_{L F}+0.6208 X_{C F}+0.9962 X_{L F}^{2} \\
& -0.0091 X_{C F}^{2}-0.4932 X_{L F} X_{C F} \\
P F= & 94.3923-0.7447 X_{L F}+4.5175 X_{C F}-0.0926 X_{L F}^{2} \\
& -1.2167 X_{C F}^{2}+0.4383 X_{L F} X_{C F}
\end{aligned}
$$

With respect to (14)-(16) the contours of the responses for THDV, THDI and PF are plotted in Figure 4 (a), (b) and (c). By searching these contours, minimum values of the THDV and THDI are found as $2.6519 \%$ and $5.5087 \%$ for the $\mathrm{X}_{\mathrm{LF}}$ and $\mathrm{X}_{\mathrm{CF}}$ coded values such as -0.1092 and -0.8182 , respectively. For the optimum case, it is also observed that PF attains 90.0010\%. Normalizing the coded values, actual values of the optimal $\mathrm{X}_{\mathrm{LF}}$ and $\mathrm{X}_{\mathrm{CF}}$ parameters are calculated as $0.1945 \Omega$ and $2.4545 \Omega$. In order to show the validity of the proposed approach, it will be evaluated with respect to Classical Direct Search Method (CDSM) [40].

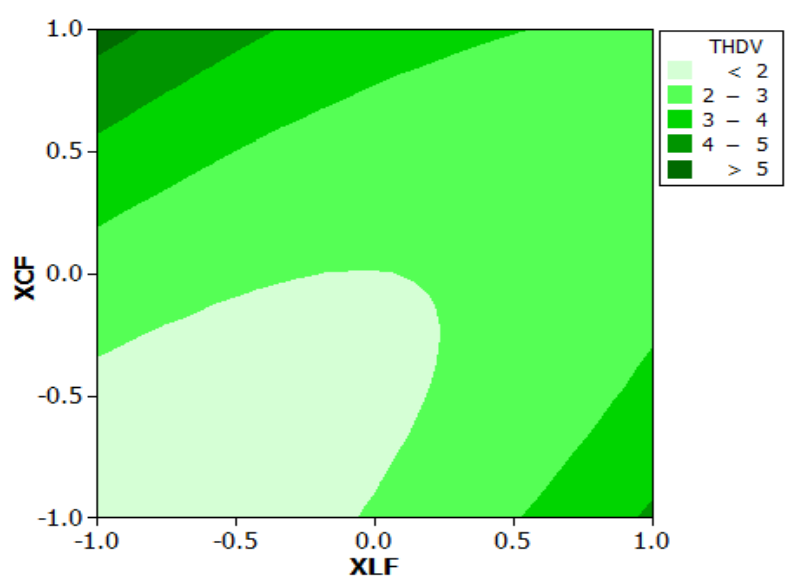

(a) THDV response

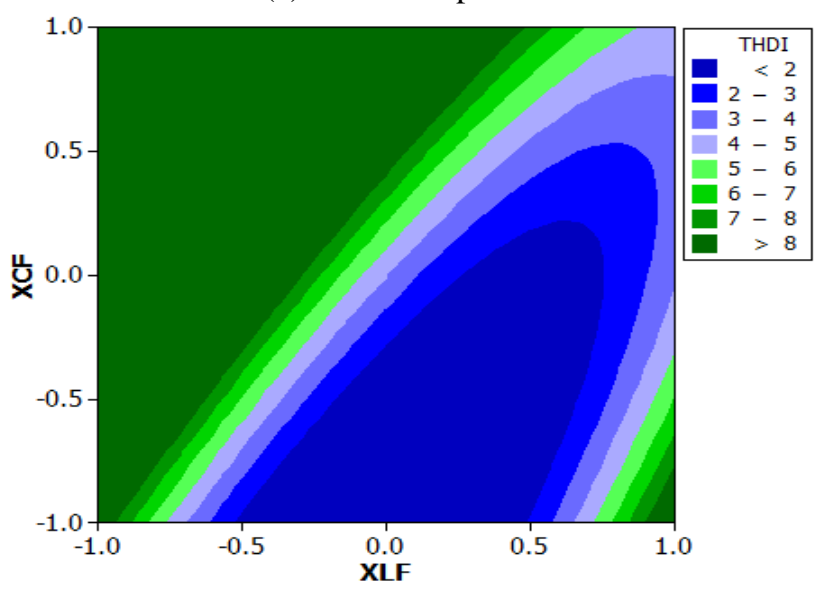

(b) THDI response 


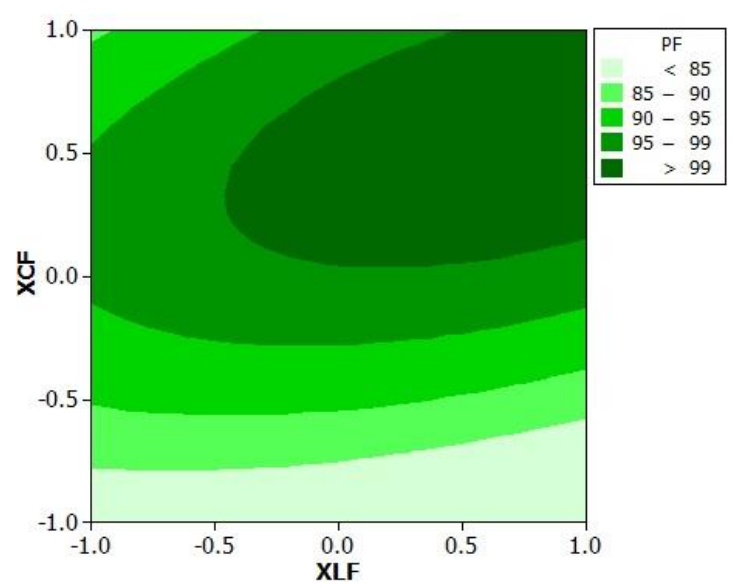

(c) PF response

Fig. 3: Contour plots of (a) THDV, (b) THDI, (c) PF responses for initial parameter set.

TABLE V

LIST OF ACTUAL AND CORRESPONDING CODED VALUES OF

\begin{tabular}{|c|c|c|c|}
\hline Levels & -1 & 0 & 1 \\
\hline $\mathrm{X}_{\mathrm{LF}}(\Omega)$ & 0.1500 & 0.2000 & 0.2500 \\
\hline $\mathrm{X}_{\mathrm{CF}}(\Omega)$ & 2.4000 & 2.7000 & 3.0000 \\
\hline
\end{tabular}

TABLE VI

DESIGN OF EXPERIMENTS MATRIX SHOWING CODED VALUES AND OBSERVED RESPONSES ACCORDING TO THE NEW PARAMETER SET

\begin{tabular}{ccccc}
\hline $\mathbf{X}_{\mathbf{L F}}$ & $\mathbf{X}_{\mathbf{C F}}$ & THDV & THDI & PF \\
\hline-1 & -1 & 2.1476 & 6.6685 & 89.7701 \\
1 & -1 & 3.1041 & 5.7660 & 87.3746 \\
-1 & 1 & 1.8634 & 9.1105 & 97.9138 \\
1 & 1 & 3.0097 & 6.2351 & 97.2716 \\
-1 & 0 & 2.0122 & 7.8065 & 95.0160 \\
1 & 0 & 3.0616 & 6.0834 & 93.5853 \\
0 & -1 & 2.7330 & 5.5326 & 88.6445 \\
0 & 1 & 2.5672 & 6.3465 & 97.7087 \\
0 & 0 & 2.6566 & 5.9672 & 94.3904 \\
\hline
\end{tabular}

B. Solution of the Formulated Optimization Problem with respect to Classical Direct Search Method

CDSM is one of the oldest and the most reliable optimization techniques, which searches all possible choices for finding the optimal solution. When CDSM is employed to design a single-tuned passive filter, by considering the formulated optimization problem, the optimal $\mathrm{X}_{\mathrm{LF}}$ and $\mathrm{X}_{\mathrm{CF}}$ values are found as $0.1880 \Omega$ and $2.4480 \Omega$, for three digits precise. For the optimal $\mathrm{X}_{\mathrm{LF}}$ and $\mathrm{X}_{\mathrm{CF}}$ parameters, THDV, THDI and PF are calculated as $2.5941 \%, 5.7060 \%$ and $90.0203 \%$, respectively. Thus, it can be concluded that the results of the proposed approach and CDSM are very close to each other, and optimal $\mathrm{X}_{\mathrm{LF}}$ and $\mathrm{X}_{\mathrm{CF}}$ values of the passive harmonic filter can successfully be found using the proposed approach.

\section{CONCLUSION}

In the literature, the optimization problem of singletuned passive filters is generally solved by the heuristic methods. These methods provide a reasonable solution (near globally optimal) in a short time or less iterations when they are compared to the conventional optimization methods. However, the success of the heuristic methods depends on the estimation of their specific parameters, which is not a straightforward process.

Consequently, in this paper, a new approach based on Response Surface Methodology (RSM) is implemented to solve the multi-objective optimization problem of the single-tuned passive filters. The objective of the proposed approach is to minimize total harmonic distortions of voltage and current (THDV and THDI) while maintaining the power factor $(\mathrm{PF})$ at its desired value.

The main advantage of the RSM is that it provides the mathematical expressions of PF, THDI and THDV in terms of the filter parameters $\left(\mathrm{X}_{\mathrm{CF}}\right.$ and $\left.\mathrm{X}_{\mathrm{LF}}\right)$. Thus, by using these expressions, it can be possible to find the optimal combination of $\mathrm{X}_{\mathrm{CF}}$ and $\mathrm{X}_{\mathrm{LF}}$. For a typical industrial power plant, the numerical results show that the proposed approach based on RSM can be used for simple, fast and accurate design of harmonic passive filters.

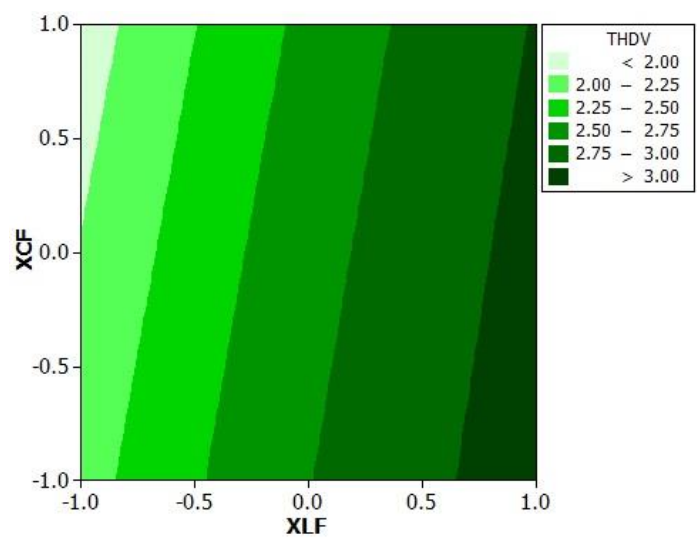

(a) THDV response

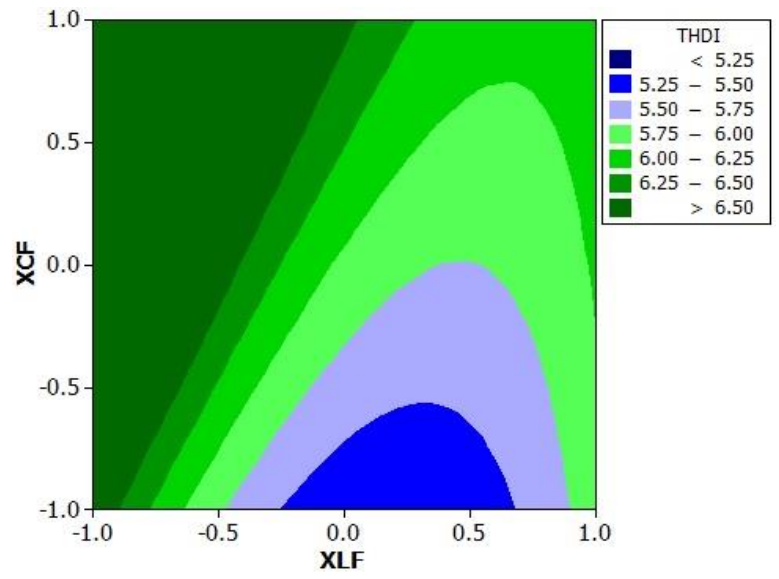

(b) THDI response 


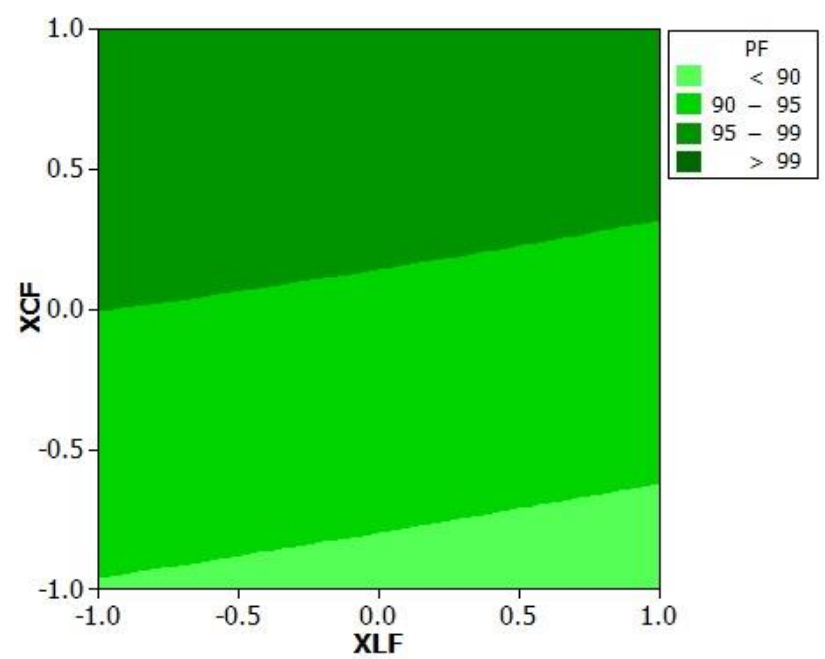

(c) PF response

Fig. 4: Contour plots of (a) THDV, (b) THDI, (c) PF responses for new (second) parameter set.

\section{REFERENCES}

[1] G. K. Singh, "Power system harmonics research: a survey", Euro Trans. Electr. Power, vol. 19, no. 2, pp. 151-172, March 2009.

[2] M. E. Balci, M.H. Hocaoglu, "New power decomposition for sinusoidal and nonsinusoidal conditions", in Proc. 2006 Int. Conf. on Harmonics and Quality of Power (ICHQP'06), 1-5 October 2006, Cascais, Portugal.

[3] M. E. Balci, M. H. Hocaoglu, "Effects of source voltage harmonics on power factor compensation in ac chopper circuits", Electrical Power Quality and Utilisation Journal, vol. 14, no. 1, pp. 53-60, August 2008.

[4] F. Z. Peng, "Harmonic sources and filtering approaches", IEEE Trans. on Ind. Appl. Mag., Vol. 7, No. 4, pp.18 -25, Jul./Aug. 2001.

[5] J. C. Das, "Passive filters - potentialities and limitations," IEEE Trans. on Ind. Appl., vol.40, no.1, pp.232-241, Jan.-Feb. 2004.

[6] A. B. Nassif, W. Xu, W. Freitas, "An investigation on the selection of filter topologies for passive filter applications", IEEE Trans. on Power Deliv., Vol. 24, No. 3, pp. 1710-1718, Jul. 2009.

[7] A. Ghamri, M. T. Benchouia, A. Golea, "Sliding-mode control based three-phase shunt active power filter: simulation and experimentation", Electric Power Components and Systems, Vol. 40, No. 4, pp. 383-398, Jan. 2012.

[8] Nitin Gupta, S. P. Singh, R. C. Bansal, "A digital signal processor based performance evaluation of three-phase four-wire shunt active filter for harmonic elimination, reactive power compensation, and balancing of non-linear loads under non-ideal mains voltages", Electric Power Components and Systems, Vol.40, No.10, pp. 1119-1148, Jul. 2012.

[9] K. M. Tsang, W. L. Chan, Xin Tang, "Multi-level shunt active power filter using modular cascade H-bridge and delay firing", Electric Power Components and Systems, Vol.41, No.6, pp. 605618, Apr.2013.

[10] B. Badrzadeh, K. S. Smith, R. C. Wilson, "Designing passive harmonic filters for an aluminum smelting plant," IEEE Trans. on Ind. Appl., Vol. 47, No. 2, pp. 973-983, Mar./Apr. 2011.

[11] S. H. E. Abdel Aleem, A. F. Zobaa, M. Mamdouh Abdel Aziz, "Optimal C-type passive filter based on minimization of the voltage harmonic distortion for nonlinear loads", IEEE Trans. on Industrial Electronics, vol. 59, no. 1, pp. 281-289, Jan. 2012.

[12] M. E. Balci, A. D. Karaoglan, "Optimal design of C-type passive filters based on response surface methodology for typical industrial power systems", Electric Power Components and Systems, vol. 41, no. 7, Apr. 2013.

[13] Y. P. Chang; C. J. Wu, "Design of harmonic filters using combined feasible direction method and differential evolution", Int. Conf. on Power System Technology 2004, vol.1, pp.812-817, 21-24 Nov. 2004, Singapore.

[14] Y. P. Chang, C. J. Wu, "Optimal multiobjective planning of large scale passive harmonic filters using hybrid differential evolution method considering parameter and loading uncertainty", IEEE Trans. on Power Delivery, vol. 20, no. 1, pp. 408-416, Jan. 2005.

[15] A. M. Sharaf, A. A. A. El-Gammal, "A novel discrete multiobjective Particle Swarm Optimization (MOPSO) of optimal shunt power filter", IEEE/PES Power Systems Conference and Exposition, pp.1-7, 15-18 March 2009, Seattle, WA.

[16] H. H. Zeineldin , A. F. Zobaa, "Particle swarm optimization of passive filters for industrial plants in distribution networks", Electric Power Components and Systems, vol. 39, no. 16, pp. 1795-1808, Oct. 2011.

[17] I. F. Mohamed, S. H. E. Abdel Aleem, A. M. Ibrahim and A. F. Zobaa, "Optimal Sizing of C-type Passive Filters under Nonsinusoidal Conditions", Energy Technology \& Policy. 1 (2014), $35-44$.

[18] P. Zacharia et al., Genetic algorithm based optimal design of shunt compensators in the presence of harmonics, Electric Power System Research. 80 (2008) 728-735.

[19] A. Menti et al., Optimal sizing and limitations of passive filters in the presence of background harmonic distortion, Electrical Engineering (Archiv fur Elektrotechnik). 91 (2009) 89-100.

[20] S.H.E. Abdel Aleem, M.E. Balci, A.F. Zobaa, and S.Sakar, "Optimal Passive Filter Design for Effective Utilization of Cables and Transformers under Non-sinusoidal Conditions," Proc. 16th Int. Conf. Harmonics and Quality of Power, ICHQP'14, Bucharest, Romania, May 25-28, 2014, pp. 626-630.

[21] S. H. E. Abdel Aleem, M. E. Balci and S. Sakar, "Effective utilization of cables and transformers using passive filters for nonlinear loads", International Journal of Energy and Power Systems. 71 (2015), 344-350.

[22] T. T. Chang, H. C. Chang, "Application of differential evolution to passive shunt harmonic filter planning", 8th Int. Conf. on Harmonics and Quality of Power, vol. 1, pp.149-153, 14-18 Oct. 1998, Athens, Greece.

[23] Y. Y. Hong, W. J. Liao, "Optimal passive filter planning considering probabilistic parameters using cumulant and adaptive dynamic clone selection algorithm", International Journal of Electrical Power \& Energy Systems, vol. 45, no. 1, pp. 159-166, Feb. 2013.

[24] M. Mohammadi, "Bacterial foraging optimization and adaptive version for economically optimum sitting, sizing and harmonic tuning orders setting of LC harmonic passive power filters in radial distribution systems with linear and nonlinear loads", Applied Soft Computing, vol. 29, pp. 345-356, Apr. 2015.

[25] Y. Y. Hong, W. F. Huang, "Interactive multiobjective passive filter planning with fuzzy parameters in distribution systems using genetic algorithms", IEEE Trans. on Power Delivery, vol. 18, no. 3, pp. 1043-1050, July. 2003.

[26] Y. P. Chang, L. Chinyao, "An ant direction hybrid differential evolution heuristic for the large-scale passive harmonic filters planning problem", Expert Systems Applications, vol. 35, no. 3, pp. 894-904, Oct. 2008.

[27] Y. P. Chang, C. N. Ko, "A PSO method with nonlinear timevarying evolution based on neural network for design of optimal harmonic filters", Expert Systems Applications, vol. 36, no. 3, pp. 6809-6816, Apr. 2009.

[28] C. N. Ko, Y. P. Chang, C. J. Wu, "A PSO method with nonlinear time-varying evolution for optimal design of harmonic filters", IEEE Trans. on Power Systems, vol. 24, no. 1, pp. 437-444, Dec. 2008.

[29] Z. Xiao-Rong, S. Xin-chun, P. Yong-long, L. He-ming, "Simulated annealing based multi-object optimal planning of passive power filters", IEEE/PES Transmission and Distribution Conference \& Exhibition 2005, pp. 1-5.

[30] M. E. Balci, "Optimal C-type filter design to maximize transformer's loading capability under non-sinusoidal conditions", Electric Power Components and Systems, vol. 42, no. 14, pp. 1565-1575, Sep. 2014.

[31] M. E. Balci, "Optimal design of single-tuned passive filters to minimize harmonic loss factor", Middle East Journal of Scientific Research, vol. 21, no. 11, pp. 2149-2155, Nov. 2014.

[32] D. F. Jones et al., Multiobjective meta-heuristics: an overview of the current state-of-the-art, European Journal Operational Research. 137 (2002) 1-9.

[33] G. E. P. Box and K. B. Wilson, On the experimental attainment of optimum conditions, Journal of Royal Statistical Society Series B. 13 (1951) $1-38$ 
XII International School on Nonsinusoidal Currents and Compensation, ISNCC 2015, Łagów, Poland

[34] D. C. Montgomery, 2001. Design and Analysis of Experiments, 5th Edition, John Wiley \&Sons, Inc., New York.

[35] Task Force Harmonic Modeling and Simulation, Modeling and simulation of the propagation of harmonics in electric power networks, IEEE Trans. Power Delivery. 11 (1996) 452-465.

[36] M. E. Balci, D. Ozturk, O. Karacasu, M. H. Hocaoglu, "Experimental verification of harmonic load models", 43rd UPEC, Padova, Italy, 1-4 Sep. 2008, pp. 1-4.

[37] IEEE Recommended Practices and Requirements for Harmonic Control in Electrical Power Systems, IEEE Standard 519-2014, 2014.
[38] M. M. Abdel Aziz et al., Power factor and your electrical utility bill in Egypt, IEEE Trans. Power Delivery. 18 (2003) 1567-1568.

[39] Minitab 16 Statistical Software, Minitab's Documentation: Using the Software and Understanding Output, http://www.minitab.com/en-TR/training/tutorials/accessing-thepower.aspx?id=1708.

[40] T. G. Kolda et al., Optimization by direct search: new perspectives on some classical and modern methods, SIAM Review. 45 (2003) $385-$ 